\title{
Incidence and risk factors for postoperative nausea and vomiting in orthognathic surgery: a 10-year retrospective study
}

\author{
Subhabrata Ghosh, Kirthi Kumar Rai, Hosadurga Rudraswamy Shivakumar, \\ Amarnath P. Upasi, Vinayak Gourish Naik, Avijit Bharat \\ Department of Oral and Maxillofacial Surgery, Bapuji Dental College and Hospital, Davangere, India
}

\begin{abstract}
J Korean Assoc Oral Maxillofac Surg 2020;46:116-124)
Objectives: Postoperative nausea and vomiting (PONV) is considered as one of the most incessant and anguishing factors for patients who have surgery under general anesthesia. The occurrence of PONV after orthognathic surgery can lead to dehydration, infection, bleeding at the surgical site, and patient discomfort, all of which leave a patient with a negative impression of anesthesia and surgery. The purpose of this study is to assess the incidence of PONV after orthognathic surgery and to correlate it with factors related to patient, anesthesia, and surgery.

Materials and Methods: A 10-year retrospective survey was done for patients who underwent orthognathic surgery between January 2008 and March 2018. The incidence of PONV was evaluated, correlations with factors related to patient, anesthesia, and surgery were studied, and the duration between the end of surgery and the occurrence of the first episode of PONV was tabulated.

Results: The medical records of 109 patients were screened, out of which 101 satisfied the inclusion criteria. Amongst these patients, 60 patients (59.4\%) suffered from PONV. Patient's sex, induction agent used, intravenous fluids administered intraoperatively, duration and type of surgery, and the presence of a nasogastric tube were seen to have a significant influence on precipitating PONV. It was noted that among the patients who suffered from PONV, $61.7 \%$ of them experienced it 48-96 hours after the end of surgery.

Conclusion: Despite the improved anesthetic equipments, drugs, and surgical techniques currently used, the incidence of PONV was high in our study. Certain factors that were seen to influence PONV in this study need to be considered in order to develop an efficacious protocol to reduce PONV in orthognathic surgeries.
\end{abstract}

Key words: Postoperative nausea and vomiting, Orthognathic surgery, General anesthesia

[paper submitted 2019. 2. 19 / revised 2019. 4. 6 / accepted 2019. 4. 8]

\section{Introduction}

It has been more than a century since Flagg highlighted three main factors for postoperative nausea and vomiting (PONV): anesthetic drugs, reflex responses, and use of opioids. Subsequent studies have revealed a plethora of other factors precipitating PONV that include age, sex, motion sickness, body habitus, surgical site, and postoperative feeding procedures ${ }^{1}$. In the present world we have witnessed phe-

\section{Subhabrata Ghosh}

Department of Oral and Maxillofacial Surgery, Bapuji Dental College and Hospital, Davangere, Karnataka 577004, India

TEL: +91-7349061363 FAX: +91-08192-220572

E-mail: sghosh878@gmail.com

ORCID: https://orcid.org/0000-0002-7641-2867

(c) This is an open-access article distributed under the terms of the Creative Commons Attribution Non-Commercial License (http://creativecommons.org/ licenses/by-nc/4.0/), which permits unrestricted non-commercial use, distribution, and reproduction in any medium, provided the original work is properly cited.

Copyright (C) 2020 The Korean Association of Oral and Maxillofacial Surgeons. All rights reserved. nomenal improvement in the field of anesthetic equipment, drugs, and surgical techniques, but PONV still remains one of the most common problems for both the patient and the surgeon. It has been reported that $36 \%$ of all surgery patients experience PONV, and the percentage increases to $40 \%$ in the case of orthognathic surgeries ${ }^{2-4}$. PONV causes discomfort and stress in the patient and may also result in dehydration, electrolyte imbalance, esophageal rupture, wound dehiscence, aspiration of gastric contents, and possibly death ${ }^{5-7}$. The significance of PONV and its management is amplified for orthognathic surgeries for the very reason that the vomitus can affect the healing of intraoral surgical wounds and may also lead to intraoral bleeding, which may further trigger nausea and vomiting due to the swallowing of blood ${ }^{3,8}$. These events can prolong the patient's stay in the hospital, thus increasing medical costs, and may leave a negative impression with the patient regarding the surgery ${ }^{5}$. Although reports in the literature suggest that the occurrence of PONV is highest amongst 
ophthalmologic, ear, intra-abdominal, and laparoscopic surgeries $^{5,9,10}$, very few studies have documented the incidence of PONV following orthognathic surgeries over a considerable postoperative period or have analyzed its risk factors. The purpose of this retrospective study was to determine the prevalence of PONV in patients undergoing orthognathic surgeries and correlate it with key factors related to the patient, anesthesia, and surgery.

\section{Materials and Methods}

This study was designed as a retrospective cross-sectional study to evaluate the prevalence of PONV in patients who underwent orthognathic surgery in the Department of Oral and Maxillofacial Surgery at Bapuji Dental College and Hospital, Davangere, India, between January 2008 and March 2018. The collected data was correlated with certain potential risk factors. The study was given ethical approval by the Institutional Review Board of Bapuji Dental College and Hospital (No. BDC/Exam/393/2017-18). All patients above the age of 14 years who underwent orthognathic surgery in maxilla, mandible, or both simultaneously were included in the study. Patients with any history of PONV, vertigo, migraine headaches, and neurological or gastrointestinal problems were excluded from the study. Patients with incomplete or illegible medical records were also excluded. Medical charts were screened by one researcher. The nursing notes indicating the incidence of PONV and the need to administer antiemetic drugs in the post anesthetic care unit (PACU) and short stay unit (SSU) were noted. Nausea, vomiting, or retching were all classified as PONV.

All postoperative patients were kept under observation in the PACU or recovery room for 1 to 2 hours and were shifted to the SSU or wards when they had adequately controlled pain, had an adequate level of consciousness, and their vital parameters were stable.

In the SSU or wards the patients were administered parenteral antibiotics as per their requirements and were given analgesics to control pain. Regular intraoral irrigation and dressing of the surgical site was done and it was ensured that postoperative oral hygiene was maintained.

The data collected from the charts were divided into three sections: 1) patient-related factors, 2) general anesthesiarelated factors, and 3) surgery-related factors.

In patient-related factors, the patient's age, sex, and body mass index (BMI) were recorded. The BMI was calculated with the formula $\mathrm{BMI}=($ body weight in $\mathrm{kg}) /($ height in me- ter) ${ }^{2}$. All of these data were taken from the patient's medical record. BMI was divided into four categories: underweight $\left(\mathrm{BMI}<18.5 \mathrm{~kg} / \mathrm{m}^{2}\right.$ ), normal weight (BMI 18.5-24.9 kg/m²), overweight (BMI 25-29.9 kg/m²), and obese (BMI $30 \mathrm{~kg} / \mathrm{m}^{2}$ or greater).

The anesthesia records were extracted from the anesthetist's chart. The induction agent used, the intraoperative intravenous (IV) fluids given per $\mathrm{kg}$ of body weight, and the administration of opioids were recorded. Over the 10-year period included in the study, all patients were anesthetized by the same anesthesiologist. All patients received a standard pre-anesthetic medication and, in all cases, general anesthesia was maintained with a mixture of nitrous oxide, oxygen, and isoflurane. The total fluid that was given intraoperatively was calculated in milliliters and was divided by the patient's body weight to obtain the IV fluids given/kg body weight. Any opioids given at the end of the surgical procedure were also noted.

In the surgery-related factors, the duration of surgery, site of surgery, and presence of nasogastric feeding tube were noted. The duration and the site of surgery was recorded from the operation theatre notes. The surgical site was divided into three categories: 1) maxillary procedures (maxillary osteotomies, palatal expansions); 2) mandibular procedures (mandibular sagittal osteotomies, distraction osteogenesis, genioplasty); and 3) bi-jaw procedures (maxillary and mandibular osteotomies). The decision for the requirement of the nasogastric tube was taken by the operating surgeon prior to the surgery. In patients where a nasogastric tube was present, gastric lavage was done postoperatively and this tube was used for feeding purpose also. The nasogastric tube was removed once the healing of the surgical wounds were adjudged to be satisfactory by the operating surgeon.

Nursing notes made in the PACU and SSUs, as well as administration of postoperative antiemetic drugs, were evaluated to determine the prevalence of PONV. The time elapsed between the end of surgery and the occurrence of first episode of PONV was also documented.

A compilation of data and percentage analysis was performed. The results were analyzed statistically using Pearson's correlation test for parametric variables and a chi-square test for non-parametric variables. Results were considered to be significant at a $5 \%$ critical level $(P<0.05)$. Statistical analysis was performed using IBM SPSS Statistics (ver. 22.0; IBM, Armonk, NY, USA). 


\section{Results}

A total of 109 medical records were analyzed in this study, out of which 101 met the inclusion criteria. Of the 101 patients, the prevalence of PONV was found to be $59.4 \%$ $(60 / 101)$.

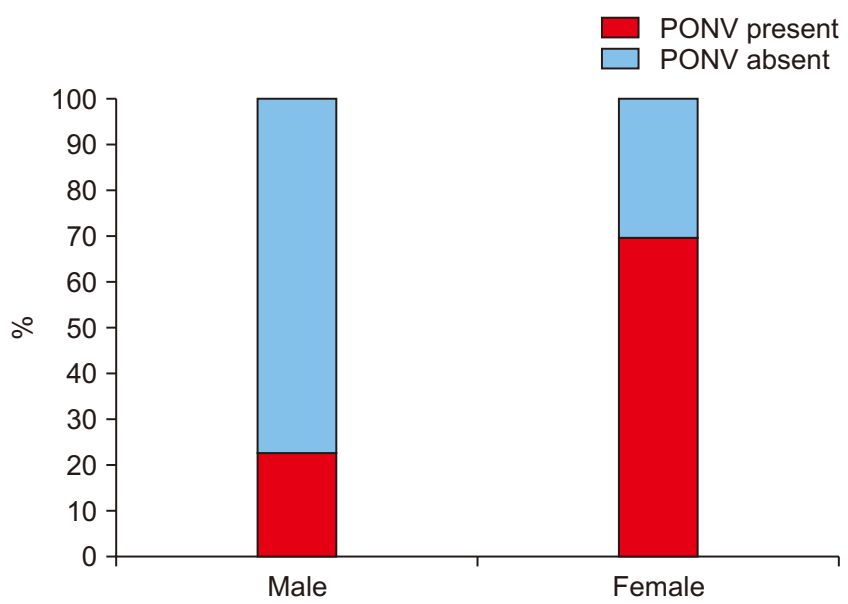

Fig. 1. Incidence (\%) of postoperative nausea and vomiting (PONV) with sex.

Subhabrata Ghosh et al: Incidence and risk factors for postoperative nausea and vomiting in orthognathic surgery: a 10-year retrospective study. J Korean Assoc Oral Maxillofac Surg 2020

\section{Patient-related factors}

In this study, $78.2 \%$ patients were female (79/101), out of which $69.6 \%(55 / 79)$ experienced PONV when compared to $22.7 \%(5 / 22)$ of the males (Fig. 1), and this was statistically significant.(Table 1) Our sample group consisted of patients in the age range of 14-28 years. It the highest prevalence of PONV was seen in the age group 19-23 years (64.3\%), but there was no statistical correlation found between age and PONV. The incidence of PONV was found to be directly proportional to BMI (underweight, 50\%; normal, 53.1\%; obese, $72 \%$; and overweight, $77.8 \%$ ) but this was not statistically significant.

\section{Anesthesia-related factors}

Among the patients who were induced by thiopentone sodium, 74.6\% (53/71) experienced PONV while only 23.3\% (7/30) of the patients who were induced by propofol experienced PONV.(Fig. 2) This effect of propofol on PONV was found to be statistically significant.(Table 1) It was noted that when less than $25 \mathrm{~mL} / \mathrm{kg}$ bodyweight of IV fluid was given intraoperatively, $41.0 \%(16 / 39)$ of the patients experienced

Table 1. Descriptive statistics of correlation between PONV and potential risk factors

\begin{tabular}{|c|c|c|c|c|c|}
\hline Potential risk factor & Sub group & No. of patients & PONV present & PONV absent & $P$-value \\
\hline \multirow[t]{3}{*}{ Age (yr) } & $14-18$ & 26 & $14(53.8)$ & $12(46.2)$ & 0.974 \\
\hline & $19-23$ & 56 & $36(64.3)$ & $20(35.7)$ & \\
\hline & $24-28$ & 19 & $10(52.6)$ & $9(47.4)$ & \\
\hline \multirow[t]{2}{*}{ Sex } & Male & 22 & $5(22.7)$ & $17(77.3)$ & $0.000^{*}$ \\
\hline & Female & 79 & $55(69.6)$ & $24(30.4)$ & \\
\hline \multirow[t]{4}{*}{ Body mass index $\left(\mathrm{kg} / \mathrm{m}^{2}\right)$} & Underweight & 18 & $9(50.0)$ & $9(50.0)$ & 0.178 \\
\hline & Normal & 49 & $26(53.1)$ & $23(46.9)$ & \\
\hline & Obese & 25 & $18(72.0)$ & $7(28.0)$ & \\
\hline & Overweight & 9 & $7(77.8)$ & $2(22.2)$ & \\
\hline \multirow[t]{2}{*}{ Induction agent } & Thiopentone & 71 & $53(74.6)$ & $18(25.4)$ & $0.000 *$ \\
\hline & Propofol & 30 & $7(23.3)$ & $23(76.7)$ & \\
\hline \multirow{2}{*}{$\begin{array}{l}\text { Intraoperative IV fluids given per kg } \\
\text { body weight }\end{array}$} & $<25 \mathrm{~mL} / \mathrm{kg}$ body weight & 39 & $16(41.0)$ & $23(59.0)$ & $-0.386^{*, 1}$ \\
\hline & $\geq 25 \mathrm{~mL} / \mathrm{kg}$ body weight & 62 & $44(71.0)$ & $18(29.0)$ & \\
\hline \multirow[t]{3}{*}{ Usage of opioids intraoperatively } & Butrephenol only & 38 & $19(50.0)$ & $19(50.0)$ & $0.004 *$ \\
\hline & Pentazocine only & 22 & $9(40.9)$ & $13(59.1)$ & \\
\hline & $\begin{array}{l}\text { Butrephenol/pentazocine and } \\
\text { tramadol at the end of the } \\
\text { procedure }\end{array}$ & 41 & $32(78.0)$ & $9(22.0)$ & \\
\hline \multirow[t]{3}{*}{ Duration of surgery (min) } & $0-180$ & 36 & $8(22.2)$ & $28(77.8)$ & $-0.468^{*, 1}$ \\
\hline & $181-360$ & 49 & $37(75.5)$ & $12(24.5)$ & \\
\hline & More than 360 & 16 & $15(93.8)$ & $1(6.3)$ & \\
\hline \multirow[t]{3}{*}{ Surgical procedures } & Mandibular procedures & 37 & $17(45.9)$ & $20(54.1)$ & $0.021 *$ \\
\hline & Maxillary procedures & 37 & $22(59.5)$ & $15(40.5)$ & \\
\hline & Bi-jaw procedures & 27 & $21(77.8)$ & $6(22.2)$ & \\
\hline \multirow[t]{2}{*}{ Nasogastric tube } & Present & 73 & $54(74.0)$ & $19(26.0)$ & $0.000 *$ \\
\hline & Absent & 28 & $6(21.4)$ & $22(78.6)$ & \\
\hline
\end{tabular}

(PONV: postoperative nausea and vomiting, IV: intravenous)

${ }^{*} P<0.05$ is statistically significant. ${ }^{1}$ Negative correlation which is statistically significant.

Values are presented as number only or number (\%).

Subhabrata Ghosh et al: Incidence and risk factors for postoperative nausea and vomiting in orthognathic surgery: a 10-year retrospective study. J Korean Assoc Oral Maxillofac Surg 2020 
PONV present

PONV absent

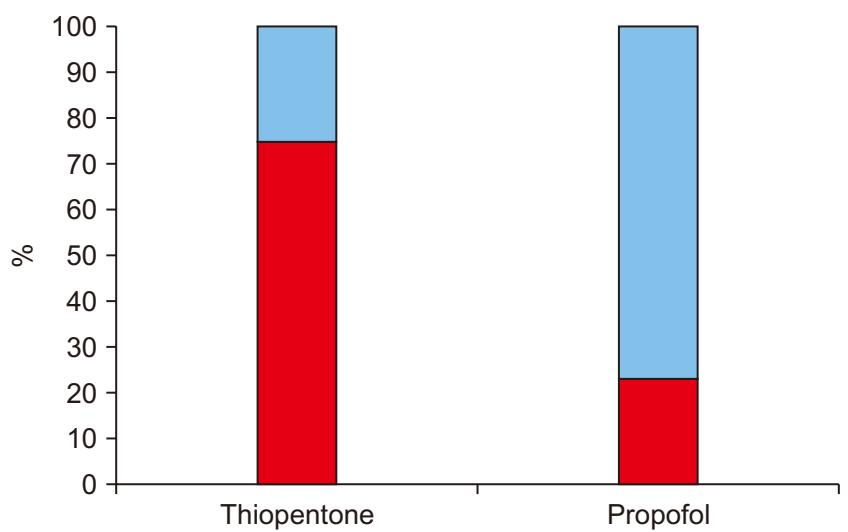

Fig. 2. Incidence (\%) of postoperative nausea and vomiting (PONV) with the agent used for induction of general anesthesia.

Subhabrata Ghosh et al: Incidence and risk factors for postoperative nausea and vomiting in orthognathic surgery: a 10-year retrospective study. J Korean Assoc Oral Maxillofac Surg 2020

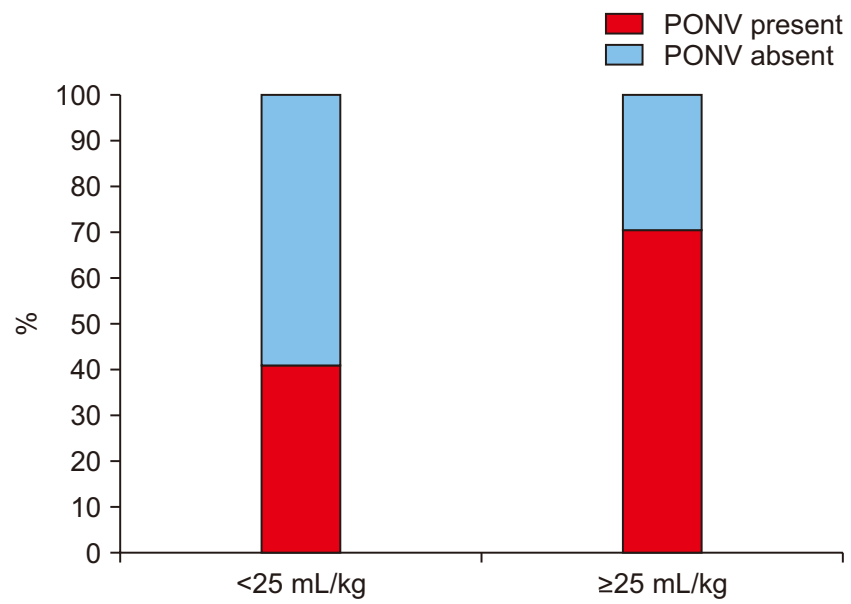

Fig. 3. Incidence (\%) of postoperative nausea and vomiting (PONV) with the intraoperative intravenous fluids given per $\mathrm{kg}$ body weight.

Subhabrata Ghosh et al: Incidence and risk factors for postoperative nausea and vomiting in orthognathic surgery: a 10-year retrospective study. J Korean Assoc Oral Maxillofac Surg 2020

PONV, which increased to $71.0 \%(44 / 62)$ when more than $25 \mathrm{~mL} / \mathrm{kg}$ bodyweight of IV fluid was given intraoperatively.

(Fig. 3) This relation between IV fluids/kg bodyweight was statistically significant.(Table 1) The incidence of PONV was seen to rise significantly $(78.1 \%)$ when an opioid (injected tramadol) was given immediately after the surgery and was statistically significant.(Fig. 4, Table 1)

\section{Surgery-related factors}

In our study group, the duration of surgery ranged from 1.5 to 9.5 hours, amongst which there was a significant in-

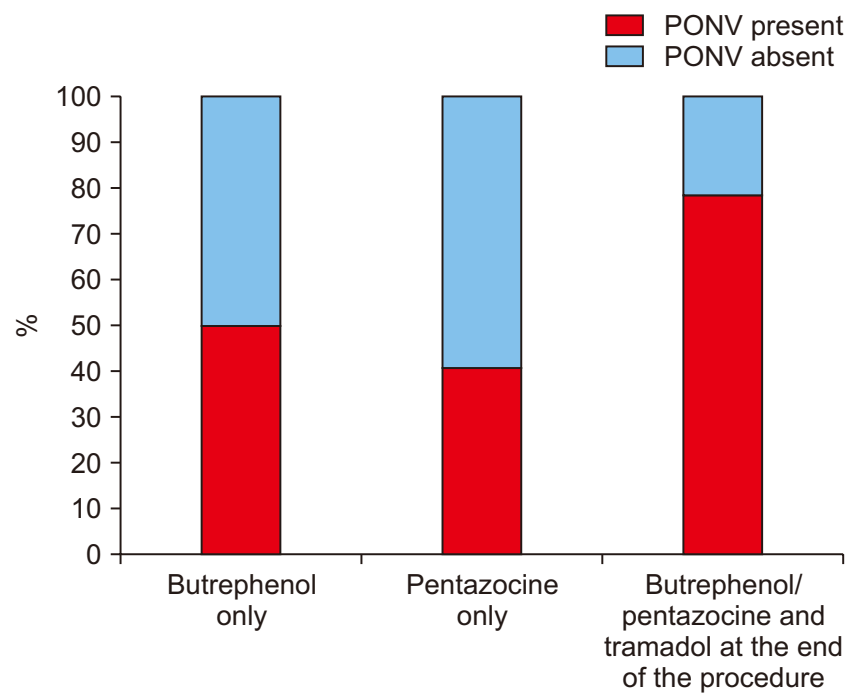

Fig. 4. Incidence (\%) of postoperative nausea and vomiting (PONV) with usage of opioids.

Subhabrata Ghosh et al: Incidence and risk factors for postoperative nausea and vomiting in orthognathic surgery: a 10-year retrospective study. J Korean Assoc Oral Maxillofac Surg 2020

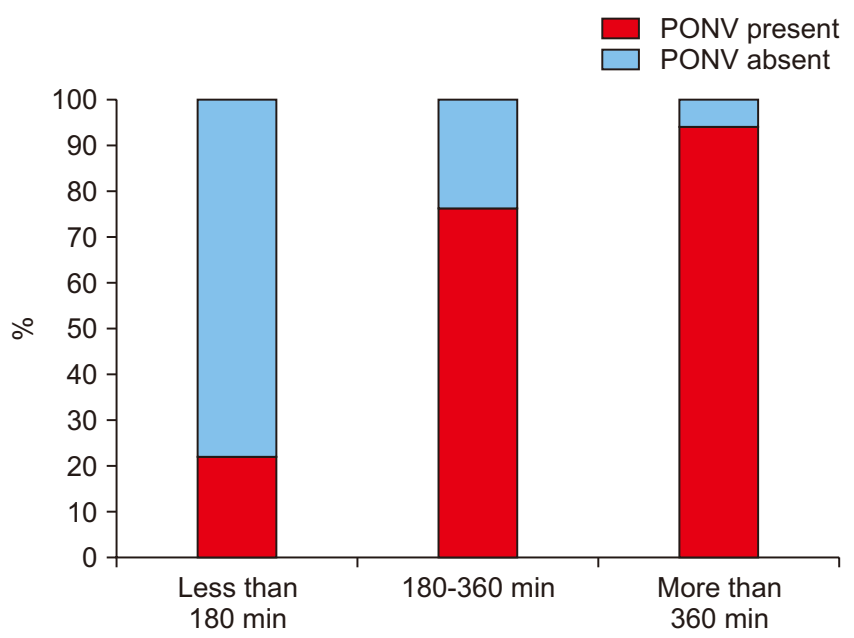

Fig. 5. Incidence (\%) of postoperative nausea and vomiting (PONV) with duration of surgery.

Subhabrata Ghosh et al: Incidence and risk factors for postoperative nausea and vomiting in orthognathic surgery: a 10-year retrospective study. J Korean Assoc Oral Maxillofac Surg 2020

crease in PONV if the surgeries lasted for more than 3 hours (1-3 hours, 22\%; more than 3 hours, 81.3\%).(Fig. 5, Table 1) Among the surgical procedures, bi-jaw surgery patients had the highest incidence of PONV (77.8\%) followed by patients who underwent only maxillary surgeries (59.5\%) and mandibular surgeries (46.0\%).(Fig. 6, Table 1) The incidence of PONV was high $(74.0 \%, 54 / 73)$ in patients who had a nasogastric tube present postoperatively when compared to patients without a nasogastric tube $(21.4 \%, 6 / 28)$.(Fig. 7, Table 1)

When the elapsed time between the first episode of PONV 


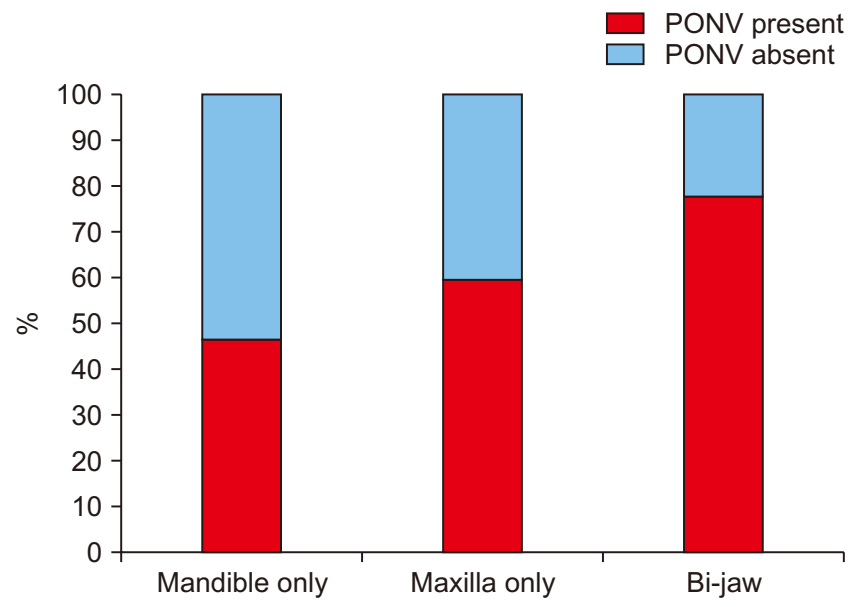

Fig. 6. Incidence (\%) of postoperative nausea and vomiting (PONV) with the surgical procedure.

Subhabrata Ghosh et al: Incidence and risk factors for postoperative nausea and vomiting in orthognathic surgery: a 10-year retrospective study. J Korean Assoc Oral Maxillofac Surg 2020

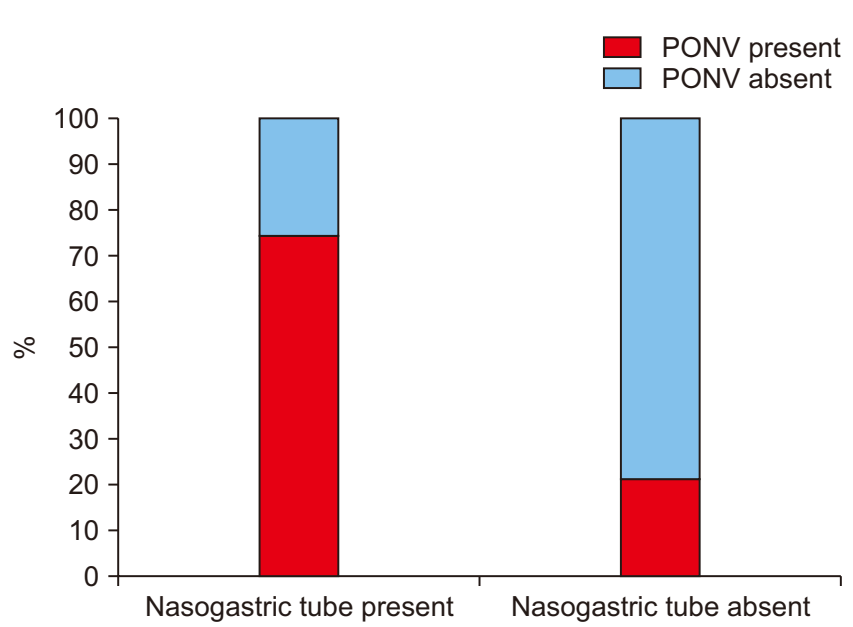

Fig. 7. Incidence (\%) of postoperative nausea and vomiting (PONV) with the presence of nasogastric tube.

Subhabrata Ghosh et al: Incidence and risk factors for postoperative nausea and vomiting in orthognathic surgery: a 10-year retrospective study. J Korean Assoc Oral Maxillofac Surg 2020

and the end of general anaesthesia was tabulated, it was seen that out of 60 patients who suffered from PONV, 37 (61.7\%) of them experienced it 48-96 hours after the end of surgery. (Fig. 8)

\section{Discussion}

This study was designed to investigate the prevalence and risk factors for PONV in patients undergoing orthognathic surgery on an inpatient basis in our unit. It has already been shown in the studies by Apfel et al. ${ }^{3}$ and Silva et al. ${ }^{4}$ that patients with any past history of PONV, motion sickness, ver-

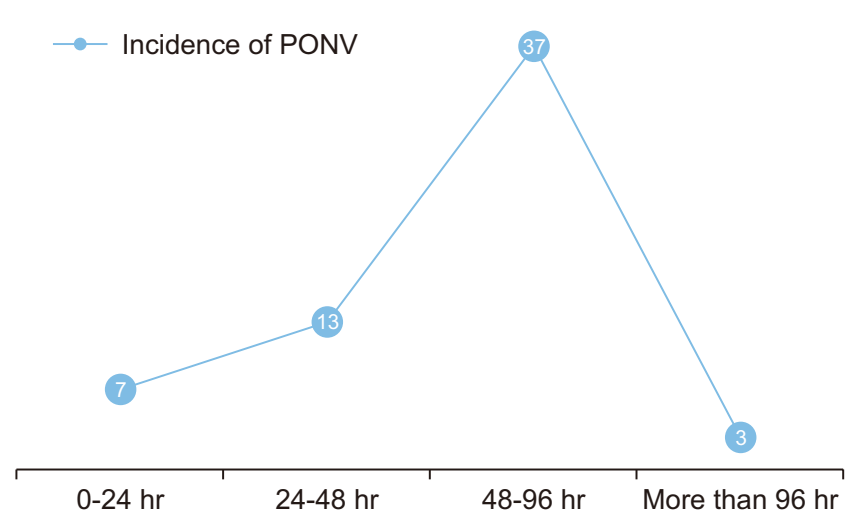

Fig. 8. Time elapsed between end of general anesthesia and first episode of postoperative nausea and vomiting (PONV).

Subhabrata Ghosh et al: Incidence and risk factors for postoperative nausea and vomiting in orthognathic surgery: a 10-year retrospective study. J Korean Assoc Oral Maxillofac Surg 2020

tigo, or migraine headaches and smoking were predisposed to have a higher prevalence of PONV, thus we decided to exclude any such patients from our study group to remove these confounding factors ${ }^{3,6,8,9-12}$. In our study patients had to be at least 14 years old to be included because the incidence of PONV in children is twice as much as in adults due to an infrequent use of premedication and opioids in the pediatric cohort $^{13-15}$. Though recent literature suggests that nausea and vomiting are two biologically different phenomenon, in this study we have considered them as one single event and have termed it as PONV. The results of this study showed a high prevalence of PONV (59.4\%) amongst our study population, which is significantly more than what was observed by Silva et al. ${ }^{4}(40.1 \%)$ and several other studies conducted in this field $(20 \%-30 \%)^{2,6,13,16,17}$, where the patients were observed for a short period of 2-3 days and thus episodes of PONV that occurred afterwards could not be tabulated. Hence, this may be the probable reason for the higher percentage of PONV in this study as it recorded all episodes of PONV during the 6 days after surgery. This observation agreed with that of Carroll et al. ${ }^{18}$, who reported that there was an over 30\% prevalence for post-discharge nausea and vomiting up to 5 days after surgery. Moreover, orthognathic surgery patients have an altered diet after surgery, have associated lip numbness, orofacial swelling, and have episodes of swallowing of blood, all of which are common in the early postoperative period and thus may be associated with the higher prevalence of $\mathrm{PONV}^{4,8}$. There is a wide range of independent factors which have been associated with PONV, out of which we have studied a few in this survey and we have broadly divided them into three sections: 1) patient-related factors; 2) anesthesia- 
related factors; and 3) surgery-related factors.

\section{Patient-related factors}

In this study there was no statistical correlation seen between the patient's age and the presence of PONV. According to Lerman ${ }^{13}$, the incidence of PONV was least in infants, increases in childhood, and remains constant or decreases slightly through adulthood (16-40 years) ${ }^{14,19-30}$. Our patient group was 14-28 years of age, which might be a possible reason for the non-significant statistical results for the PONV incidence in this age group. Also, the relationship between the incidence of PONV and age has been difficult to clarify, partly because of the confounding effects of uncontrolled variables such as sex, surgical case mix, anesthetic medications, and duration of surgery ${ }^{13}$.

Also, 79 out of 101 patients in our patient group were females and the results showed an approximate increase of $40 \%$ in the prevalence of PONV among females when compared with males (male, 22.7\%; female, 69.6\%). This result shows a significant influence of sex on the prevalence of PONV. This may be because of the intense fluctuations in the female sex hormone concentrations during the menstrual cycle, with the greatest incidence of PONV in adult females occurring during the third and fourth week of the menstrual cycle ${ }^{31,32}$.

The relation between BMI and PONV is controversial. While some studies have found an increase in the prevalence of PONV with an increase in $\mathrm{BMI}^{8}$, others have failed to find any significant relationship between the two ${ }^{4}$. Our study did not find any statistical significance between BMI and PONV, but it was observed that with an increase in BMI, the incidence of PONV increased. This may be attributed to the fact that the generous fatty tissue in obese patients could act as a long-term storage area, thus prolonging the adverse effects of some lipid soluble emetogenic drugs, especially in surgeries that go for more than 3 hours ${ }^{2,8}$.

\section{Anesthesia-related factors}

Several studies conducted in the past on the effect of general anesthesia on PONV have highlighted several independent factors affecting its incidence. In our study group, all of the cases were operated under the vigilance of a single anesthetist and in all cases patient endotracheal intubation was done and nitrous oxide was used along with isoflurane to maintain the anaesthesia. This might be another reason for the higher prevalence of PONV noted amongst our patients because it has been substantiated in previous studies that both endotracheal intubation and nitrous oxide an associated with an increased incidence of PONV ${ }^{6,7,12,33-35}$. Moreover comparative studies have shown a much lower incidence of PONV with the usage of isoflurane (4\%) when compared to desflurane (67\%) and sevofluorane (36\%), which may be because of the higher solubility of isoflurane compared to desfluorane and sevofluorane ${ }^{36}$.

Of all patients, $70.5 \%$ induced by thiopentone suffered from PONV while only $25.9 \%$ induced by propofol suffered the same, suggesting a statistically significantly negative influence of propofol on the prevalence of PONV $(P=0.415$, $P<0.5)$. This result is in harmony with several other studies that substantiate that propofol, when used as an induction agent, possesses antiemetic properties and thus can be employed as a combination prophylaxis against $\mathrm{PONV}^{37-39}$.

In our study a statistically significant correlation was seen to exist between PONV and the intraoperative IV fluids given per $\mathrm{kg}$ of body weight. It was seen that the patients who received $\geq 25 \mathrm{~mL} / \mathrm{kg}$ of IV fluids intraoperatively were more likely to experience PONV. Though pre-existing guidelines encourage hydration to minimize the risk of PONV ${ }^{11,33,40}$, this study reflected otherwise, which may be because of an increased duration of anesthesia and surgery, associated with an increase in IV fluid administration ${ }^{41}$.

In our hospital, an injection of an antiemetic prophylaxis (ondansetron $4 \mathrm{mg}$ IV) was given to all adult patients along with the general anesthesia reversal agents. This may be one of the reasons for the low incidence of PONV in the first 24 hours after surgery. Though ondansetron is shown to have a good antiemetic effect without many side effects, drugs like granisetron have been seen to have better effects on reducing the incidence of PONV in the first 24 hours after surgery and may be a viable alternative ${ }^{42}$.

The incidence of PONV when evaluated against the administration of opioids was seen to be maximum (78.1\%) when tramadol was given at the end of the procedure which was statistically significant. The etiology of PONV after opioid usage can be traced back to three mechanisms. First, the chemoreceptor trigger zone is stimulated by opioids, which releases dopamine and serotonin, thus activating the emetic center of the brain. Second, opioids result in a reduction of gastric motility, further leading to dopamine and serotonin release from afferent visceral fibers and thus activating the medullary vomiting center. Lastly, opioids sensitize the middle ear to movement, thus resulting histamine and acetylcholine release, which activates the medullary vomiting 
center $^{43-46}$.

\section{Surgery-related factors}

The impact of orthognathic surgery on PONV has been controversial. In 2007, the Society for Ambulatory Anesthesia (SAMBA) consensus guidelines mentioned orthognathic surgery as a high-risk factor for PONV, though it was removed later in $2014^{11,33,40}$. However, the high prevalence of PONV seen in this study and in subsequent studies ${ }^{4,41}$ advocates for more importance to be given to this genre of surgeries with respect to PONV. Amongst the various surgical factors, we evaluated the correlation between PONV and surgery duration, the surgical site, and the use of a nasogastric tube.

Duration of surgery has been seen to affect the incidence of PONV in various studies in the past ${ }^{9,11,33,47}$ and it was no different in this study. When the surgery lasted less than 3 hours the prevalence of PONV was only $22.2 \%$ (8/36), which increased significantly after prolonged procedures (3-6 hours, $75.5 \%$; more than 6 hours, $93.8 \%$ ). The probable reasons for the effect of surgery duration on the incidence of PONV may be the increased effects of premedication, the accumulation of emetogenic anesthetic drugs, including nitrous oxide, prolonged fasting, and increased pain in surgeries of longer duration $^{2,47}$. It is believed that when a surgery lasts for more than 3 hours, the effect of BMI on PONV also comes into play, as the lipids in the body serve as a reservoir for emetogenic $\operatorname{drugs}^{2,8}$.

It was also noted that a higher number of episodes of PONV were seen in patients undergoing maxillary and bi-jaw surgeries. Maxillary procedures usually result in greater postoperative bleeding, swallowing of blood, and are associated with the use of hypotensive anesthesia, all of which result in a higher incidence of PONV. However, a higher incidence of PONV with bi-jaw surgeries may be due to the greater average length of the surgical procedures and the involvement of the maxilla, both of which may predispose the patient to PONV $^{2,4,41}$.

The role of a nasogastric tube on PONV has been controversial. One school of thought reasons it has a beneficial role in that it aids expelling old blood from the stomach. Another group believes an indwelling tube acts as a chronic irritant to the throat and stomach and precipitates PONV by stimulation of the glossopharyngeal nerve ${ }^{33,41,48-50}$. In our study it was seen that $74.0 \%$ of the patients who had a nasogastric tube suffered from PONV while the percentage reduced to $21.4 \%$ when there was none.
One of the unique features of this study was the prolonged monitoring of PONV in the patients. The data suggests an unusual spike in the prevalence of PONV between 48-96 hours after surgery, and advocates for further research in this field to find the possible reason.

\section{Conclusion}

It was seen that there was a high prevalence of PONV amongst orthognathic surgery patients and there were significant correlations between PONV and certain patient-, anaesthesia-, and surgery-related factors. Thus, in order to improve the perioperative management of PONV, an extensive understanding of its causes and risk factors is essential. Preoperative assessment should have a detailed protocol that includes a tool for risk assessment and to label high risk patients for PONV so that prophylactic steps can be taken to reduce its occurrence.

\section{ORCID}

Subhabrata Ghosh, https://orcid.org/0000-0002-7641-2867

Kirthi Kumar Rai, https://orcid.org/0000-0001-9745-177X

Hosadurga Rudraswamy Shivakumar, https://orcid.org/00000002-0210-9590

Amarnath P. Upasi, https://orcid.org/0000-0003-2095-7347

Vinayak Gourish Naik, https://orcid.org/0000-0002-0323-8589

Avijit Bharat, https://orcid.org/0000-0002-8383-2093

\section{Authors' Contributions}

S.G. took part in conceptualising, study design collecting of data and writing of manuscript. K.K.R. took part in conceptualising and writing of manuscript. H.R.S., A.P.U., and V.G.N. did revision and correction of manuscript. A.B. did data collection and statistical analysis along with S.G.

\section{Ethics Approval and Consent to Participate}

The study was given ethical approval by the Institutional Review Board of Bapuji Dental College and Hospital (No. BDC/Exam/393/2017-18), and the informed consent was waived.

\section{Conflict of Interest}

No potential conflict of interest relevant to this article was 
reported.

\section{References}

1. Flagg PJ. The art of anaesthesia. Philadelphia (PA): Lippincott; 1916:288.

2. Kovac AL. Prevention and treatment of postoperative nausea and vomiting. Drugs 2000;59:213-43.

3. Apfel CC, Läärä E, Koivuranta M, Greim CA, Roewer N. A simplified risk score for predicting postoperative nausea and vomiting: conclusions from cross-validations between two centers. Anesthesiology 1999;91:693-700.

4. Silva AC, O'Ryan F, Poor DB. Postoperative nausea and vomiting (PONV) after orthognathic surgery: a retrospective study and literature review. J Oral Maxillofac Surg 2006;64:1385-97.

5. Gold BS, Kitz DS, Lecky JH, Neuhaus JM. Unanticipated admission to the hospital following ambulatory surgery. JAMA 1989;262:3008-10.

6. Watcha MF, White PF. Postoperative nausea and vomiting. Its etiology, treatment, and prevention. Anesthesiology 1992;77:162-84.

7. Clarke RS. Nausea and vomiting. Br J Anaesth 1984;56:19-27.

8. Koivuranta M, Läärä E, Snåre L, Alahuhta S. A survey of postoperative nausea and vomiting. Anaesthesia 1997;52:443-9.

9. Apfel CC, Heidrich FM, Jukar-Rao S, Jalota L, Hornuss C, Whelan $\mathrm{RP}$, et al. Evidence-based analysis of risk factors for postoperative nausea and vomiting. Br J Anaesth 2012;109:742-53.

10. Stadler M, Bardiau F, Seidel L, Albert A, Boogaerts JG. Difference in risk factors for postoperative nausea and vomiting. Anesthesiology 2003;98:46-52.

11. Gan TJ. Risk factors for postoperative nausea and vomiting. Anesth Analg 2006;102:1884-98.

12. Palazzo MG, Strunin L. Anaesthesia and emesis. I: etiology. Can Anaesth Soc J 1984;31:178-87.

13. Lerman J. Surgical and patient factors involved in postoperative nausea and vomiting. Br J Anaesth 1992;69(7 Suppl 1):24S-32S.

14. Cohen MM, Cameron CB, Duncan PG. Pediatric anesthesia morbidity and mortality in the perioperative period. Anesth Analg 1990;70:160-7

15. Cohen MM, Duncan PG, Pope WD, Wolkenstein C. A survey of 112,000 anaesthetics at one teaching hospital (1975-83). Can Anaesth Soc J 1986;33:22-31.

16. Cohen MM, Duncan PG, DeBoer DP, Tweed WA. The postoperative interview: assessing risk factors for nausea and vomiting. Anesth Analg 1994;78:7-16.

17. Quinn AC, Brown JH, Wallace PG, Asbury AJ. Studies in postoperative sequelae. Nausea and vomiting--still a problem. Anaesthesia 1994:49:62-5.

18. Carroll NV, Miederhoff P, Cox FM, Hirsch JD. Postoperative nausea and vomiting after discharge from outpatient surgery centers. Anesth Analg 1995;80:903-9.

19. Rowley MP, Brown TC. Postoperative vomiting in children. Anaesth Intensive Care 1982;10:309-13.

20. Schreiner MS, Nicolson SC, Martin T, Whitney L. Should children drink before discharge from day surgery? Anesthesiology 1992;76:528-33.

21. Smessaert A, Schehr CA, Artusio JF Jr. Nausea and vomiting in the immediate postanesthetic period. J Am Med Assoc 1959;170:20726.

22. Vance JP, Neill RS, Norris W. The incidence and aetiology of postoperative nausea and vomiting in a plastic surgical unit. Br J Plast Surg 1973;26:336-9.

23. Woods AM, Berry FA, Carter BJ. Strabismus surgery and postoperative vomiting: clinical observations and review of the current literature; a medical opinion. Paediatr Anaesth 1992;2:223-9.

24. Bellville JW, Bross ID, Howland WS. Postoperative nausea and vomiting. IV. Factors related to postoperative nausea and vomiting. Anesthesiology 1960;21:186-93.

25. Burrow BJ. The patient's view of anaesthesia in an Australian teaching hospital. Anaesth Intensive Care 1982;10:20-4.

26. Burtles R, Peckett BW. Postoperative vomiting; some factors affecting its incidence. Br J Anaesth 1957;29:114-23.

27. Cohen MM, Duncan PG, Pope WD, Biehl D, Tweed WA, MacWilliam L, et al. The Canadian four-centre study of anaesthetic outcomes: II. can outcomes be used to assess the quality of anaesthesia care? Can J Anaesth 1992;39(5 Pt 1):430-9.

28. Dodds CP, Harding MI, More DG. Anaesthesia in an Australian private hospital: the consumer's view. Anaesth Intensive Care $1985 ; 13: 325-9$

29. Keep PJ, Jenkins JR. From the other end of the needle. The patient's experience of routine anaesthesia. Anaesthesia 1978;33:8302.

30. Purkis IE. Factors that influence postoperative vomiting. Can Anaesth Soc J 1964;11:335-53.

31. Beattie WS, Lindblad T, Buckley DN, Forrest JB. The incidence of postoperative nausea and vomiting in women undergoing laparoscopy is influenced by the day of menstrual cycle. Can J Anaesth 1991;38:298-302.

32. Honkavaara P, Lehtinen AM, Hovorka J, Korttila K. Nausea and vomiting after gynaecological laparoscopy depends upon the phase of the menstrual cycle. Can J Anaesth 1991;38:876-9.

33. Gan TJ, Diemunsch P, Habib AS, Kovac A, Kranke P, Meyer TA, et al. Consensus guidelines for the management of postoperative nausea and vomiting. Anesth Analg 2014;118:85-113.

34. Fernández-Guisasola J, Gómez-Arnau JI, Cabrera Y, del Valle SG. Association between nitrous oxide and the incidence of postoperative nausea and vomiting in adults: a systematic review and metaanalysis. Anaesthesia 2010;65:379-87.

35. Rabey PG, Smith G. Anaesthetic factors contributing to postoperative nausea and vomiting. Br J Anaesth 1992;69(7 Suppl 1):40S$45 \mathrm{~S}$.

36. Karlsen KL, Persson E, Wennberg E, Stenqvist O. Anaesthesia, recovery and postoperative nausea and vomiting after breast surgery. A comparison between desflurane, sevoflurane and isoflurane anaesthesia. Acta Anaesthesiol Scand 2000;44:489-93.

37. Hofer CK, Zollinger A, Büchi S, Klaghofer R, Serafino D, Bühlmann S, et al. Patient well-being after general anaesthesia: a prospective, randomized, controlled multi-centre trial comparing intravenous and inhalation anaesthesia. Br J Anaesth 2003;91:6317.

38. McCollum JS, Milligan KR, Dundee JW. The antiemetic action of propofol. Anaesthesia 1988;43:239-40.

39. Borgeat A, Wilder-Smith OH, Saiah M, Rifat K. Subhypnotic doses of propofol possess direct antiemetic properties. Anesth Analg 1992;74:539-41.

40. Gan TJ, Meyer TA, Apfel CC, Chung F, Davis PJ, Habib AS, et al. Society for Ambulatory Anesthesia guidelines for the management of postoperative nausea and vomiting. Anesth Analg 2007;105:1615-28.

41. Phillips C, Brookes CD, Rich J, Arbon J, Turvey TA. Postoperative nausea and vomiting following orthognathic surgery. Int J Oral Maxillofac Surg 2015;44:745-51.

42. Savant K, Khandeparker RV, Berwal V, Khandeparker PV, Jain H. Comparison of ondansetron and granisetron for antiemetic prophylaxis in maxillofacial surgery patients receiving general anesthesia: a prospective, randomised, and double blind study. J Korean Assoc Oral Maxillofac Surg 2016;42:84-9.

43. Jolley S. Managing post-operative nausea and vomiting. Nurs Stand 2001; 15:47-52; quiz 53-5.

44. McNicol E, Horowicz-Mehler N, Fisk RA, Bennett K, GialeliGoudas M, Chew PW, et al. Management of opioid side effects in cancer-related and chronic noncancer pain: a systematic review. J Pain 2003;4:231-56. 
45. Swegle JM, Logemann C. Management of common opioid-induced adverse effects. Am Fam Physician 2006;74:1347-54.

46. Flake ZA, Scalley RD, Bailey AG. Practical selection of antiemetics. Am Fam Physician 2004;69:1169-74.

47. Sinclair DR, Chung F, Mezei G. Can postoperative nausea and vomiting be predicted? Anesthesiology 1999;91:109-18.

48. Steely RL, Collins DR Jr, Cohen BE, Bass K. Postoperative nausea and vomiting in the plastic surgery patient. Aesthetic Plast Surg 2004;28:29-32.

49. Jones JE, Tabaee A, Glasgold R, Gomillion MC. Efficacy of gastric aspiration in reducing posttonsillectomy vomiting. Arch Otolaryngol Head Neck Surg 2001;127:980-4.

50. Trépanier CA, Isabel L. Perioperative gastric aspiration increases postoperative nausea and vomiting in outpatients. Can J Anaesth 1993;40:325-8.

How to cite this article: Ghosh S, Rai KK, Shivakumar HR, Upasi AP, Naik VG, Bharat A. Incidence and risk factors for postoperative nausea and vomiting in orthognathic surgery: a 10-year retrospective study. J Korean Assoc Oral Maxillofac Surg 2020;46:116124. https://doi.org/10.5125/jkaoms.2020.46.2.116 